\title{
Rechtsprechung
}

\section{Zur (drohenden) Beschlagnahme nach US-amerikanischem Recht als möglicher Rechtsmangel eines in Deutschland geschlossenen Kaufvertrages}

Landgericht Köln, Urteil vom 24. April 2013 - 23 O 266/12

1. Auch ausländische Rechte können einen Rechtsmangel darstellen. Dies setzt jedoch voraus, dass für das geltend gemachte ausländische Recht eine Entsprechung in der deutschen Rechtsordnung besteht.

2. Im Falle eines Schadenersatzes wegen einer vorvertraglichen Pflichtverletzung im Hinblick auf eine nach Vertragsschluss erfolgten Beschlagnahme eines in Deutschland erworbenen Gemäldes in den USA beginnt die Verjährung nicht erst mit der tatsächlichen Beschlagnahme durch die US-Behörden, vielmehr ist der Anspruch schon mit der Ausfuhr in die USA entstanden, weil ein etwaiger Beschlagnahmeanspruch und damit die Gefahr des Verlustes des Gemäldes bereits zu diesem Zeitpunkt bestanden hat. (Leitsätze der Redaktion)

\section{Tatbestand}

- Die Klägerin ist eine US-amerikanische Kapitalgesellschaft, die mit Kunstwerken handelt. Die Beklagte zu 1) betreibt ein Kunstauktionshaus in Köln. Sie ist Rechtsnachfolgerin des Beklagten zu 2), der das Auktionshaus im Jahr 2000 als Einzelkaufmann führte K.L. Die Beklagten sind weiterhin Rechtsnachfolger des J.H., der das Auktionshaus im Jahr 1937 unter der Firma „M.L." führte.

Im Frühjahr 2000 übersandte der Beklagte zu 2) der Klägerin den Katalog zu einer am 20. Mai 2000 stattfindenden Auktion. Unter der Losnummer 625 bot der Beklagte zu 2) das streitgegenständliche Gemälde „Der heilige Hieronymus mit dem Löwen und zwei Engeln“ zum Verkauf an. Die Katalogbeschreibung gab an, dass das Bild bereits am 13. November 1937 von L. angeboten und versteigert worden war und sich bis dahin im Eigentum der Galerie S. in Düsseldorf befunden hatte. Die Provenienzangabe lautete:

„Privatsammlung, Berlin (1933); Galerie S., Düsseldorf; 392. L.-Auktion Köln, 13.11.1937, Lot 185 (die Bestände der Galerie S., Düsseldorf); rheinische Privatsammlung; Zürich."

Am 18. Mai 2000 übersandte ein Mitarbeiter des Beklagten zu 2) der Klägerin ein Fax mit folgendem Inhalt:

„The provenance and history oft he painting is clean. We sold it 1937 (Die Bestände der Galerie S., Düsseldorf) to a collector in the Rhine area (near Cologne)."

Mit Fax vom 19. Mai 2000 bat der Geschäftsführer der Klägerin bei dem Beklagten zu 2) um Bestätigung, dass das Art Loss Register konsultiert worden war und es kein Problem hinsichtlich Diebstahls, Konfiszierung oder Zwangsverkauf gebe. Daraufhin erhielt er ein Fax, wonach das Art Loss Register den Katalog kontrolliere.
Am 20. Mai 2000 bot die Klägerin in der stattfindenden Auktion auf das Gemälde und erhielt den Zuschlag bei einem Preis von 100.000 DM nebst 16.000 DM Aufgeld. Die Klägerin zahlte den Kaufpreis und ließ das Bild am 31. Mai 2000 nach New York transportieren.

Am 22. April 2009 veröffentlicht die Zeitung "New York Times" einen Artikel über die Restitution eines Gemäldes eines unbekannten niederländischen Meisters aus dem Jahr 1632. Das Gemälde hatte sich, wie auch das streitgegenständliche Gemälde, bis 1937 im Eigentum der Galerie S. in Düsseldorf befunden und wurde in derselben Auktion 1937 versteigert. Der Geschäftsführer der Klägerin las den Artikel und stellte weitere Nachforschungen an. Hierzu kontaktierte er u.a. das Art Loss Register. Dort war das Gemälde mittlerweile als vom NS-Regime gestohlen vermerkt (seit 2004). Der Direktor des Art Loss Registers verwies den Geschäftsführer der Klägerin für weitere Nachfragen an den Leiter des "M. S. Restitution Project", einer Abteilung der Concordia Universität Montreal, welche sich um die Wiederbeschaffung der zwangsverkauften Kunstwerke M. S. bemüht. Der Leiter des Projekts, Herr E. bestätigte, dass das streitgegenständliche Bild im Jahr 1937 bei dem Rechtsvorgänger der Beklagten versteigert worden war. Herr E. informierte nach dem Gespräch sofort das Heimatschutzministerium, woraufhin sich der zuständige Bundesstaatsanwalt an die Klägerin wandte, einen Beschlagnahmeanspruch der Vereinigten Staaten geltend machte und die Herausgabe des Bildes verlangte. Am 27./28. April 2009 unterzeichnete der Geschäftsführer der Klägerin eine "Stipulation", mit welcher die Klägerin der Beschlagnahme durch die amerikanischen Behörden zustimmte. Mit Schreiben vom 22. Juni 2012 bestätigte das Justizministerium der Vereinigten Staaten der Klägerin später, dass die Vereinigten Staaten einen Anspruch darauf hätten, das streitgegenständliche Bild bei der Klägerin zu beschlagnahmen und dass aufgrund dieses Anspruchs die "Stipulation“ zustande gekommen sei. 
Die Klägerin nahm noch im Jahr 2009 Kontakt zu der Beklagten zu 1) auf, welche Entschädigungszahlungen allerdings ablehnte. Erst mit anwaltlichem Schreiben vom 15. März 2012 griff die Klägerin den Sachverhalt dann erneut auf und bot der Beklagten zu 1) Gespräche an. Im sich anschließenden Schriftwechsel lehnte die Beklagte zu 1) Zahlungen ab und wies das Gesprächsangebot zurück.

Das streitgegenständliche Werk war 1937 durch den Rechtsvorgänger der Beklagten in einer Versteigerung verkauft worden. M. S. war durch das NS-Regime zum Verkauf gezwungen worden. 1964 war das Land Nordrhein-Westfalen vom Landgericht Düsseldorf verurteilt worden, eine Entschädigung an S. zu zahlen (den sog. Verschleuderungsschaden).

Die Klägerin behauptet, dass der Beklagte zu 2) in einem Telefonat am 17. Mai 2000 garantiert habe, dass es mit Blick auf die Auktion von 1937 keine Probleme mit dem Bild gebe. Des Weiteren habe er angegeben, dass es sich bei der Galerie S. nicht um eine jüdische Galerie gehandelt habe. Sie ist der Ansicht, dass sie einen Anspruch auf Schadensersatz habe, da das Gemälde mit einem Rechtsmangel behaftet gewesen sei.

Die Klägerin beantragt,

die Beklagten zu verurteilen, als Gesamtschuldner an sie 350.000 US Dollar nebst Zinsen in Höhe von 8 Prozentpunkten über dem Basiszinssatz seit dem 2. Juni 2012 zu zahlen.

Die Beklagten beantragen,

die Klage abzuweisen.

Die Beklagten behaupten, dass die Klägerin nach amerikanischem Recht nicht verpflichtet gewesen sei, das Gemälde zurückzugeben. Im Übrigen sind sie der Ansicht, dass ein ausländisches Recht ohnehin nie einen Rechtsmangel begründen könne. Des Weiteren erheben sie die Einrede der Verjährung.

\section{Entscheidungsgründe}

Die Klage ist zulässig aber unbegründet.

Die Klägerin hat keinen Anspruch auf Schadensersatz gemäß $\S \S$ 434, 440, 325 Abs. 1 BGB a. F. Zwar ist das Mängelgewährleistungsrecht grundsätzlich anwendbar, jedoch fehlt es an einem Rechtsmangel des streitgegenständlichen Gemäldes bei Gefahrübergang.

Das Mängelgewährleistungsrecht ist anwendbar, da die Klägerin Eigentum erhalten hat. Nach überwiegender Auffassung - sowohl zum alten als auch zum neuen Kaufrecht - ist die Eigentumsverschaffung eine Hauptpflicht des Kaufvertrages, deren Verletzung keine Mängelansprüche auslöst, sondern den Erfüllungsanspruch fortbestehen lässt.
Ursprünglich war M. S. Eigentümer. Die Frage, ob er durch die Versteigerung im Jahr 1937, bei der es sich um einen Zwangsverkauf handelte, das Eigentum verloren hat, kann offen bleiben. Die Klägerin hat das Eigentum an dem streitgegenständlichen Gemälde im Jahr 2000 in jedem Fall gutgläubig erworben. Dabei richtet sich der Eigentumserwerb - einschließlich der Vorschriften über den guten Glauben - nach deutschem Recht, da der Eigentumserwerb bereits in Deutschland abgeschlossen war. Der Eigentumsübergang setzt nach deutschem Recht gemäß § 929 BGB Einigung und Übergabe voraus. Diese erfolgten noch in Deutschland. Der Transport des Bildes in die USA wurde von der Klägerin organisiert. Damit ist die Übergabe in Deutschland mit Aushändigung des Bildes an den Spediteur erfolgt. Der Spediteur wurde dabei als Geheißperson der Klägerin tätig. Die Übergabe an die Klägerin erfolgte auf ihr Geheiß an einen Dritten, nämlich an den Spediteur. Die dingliche Einigung wurde konkludent bereits bei Abschluss des Kaufvertrages erklärt. Die Klägerin war auch gutgläubig. Der gutgläubige Erwerb scheitert auch nicht daran, dass das Gemälde - wegen des Zwangsverkaufs - unter Umständen abhanden gekommen im Sinne des $\S 935$ Abs. 1 BGB war. Denn die Klägerin hat das Gemälde gemäß § 935 Abs. 2 BGB im Rahmen einer öffentlichen Versteigerung erworben.

Das Gemälde hatte jedoch keine Rechtsmängel im Sinne von $\S 434$ BGB a. F. Ein solcher liegt vor, wenn von Dritten aufgrund eines privaten oder öffentlichen Rechts das Eigentum, der Besitz oder der unbeschränkte Gebrauch des Kaufgegenstandes beeinträchtigt werden kann. Unerheblich ist dabei, ob der Dritte sein Recht erst nach Gefahrübergang ausübt. Der Verkäufer ist verpflichtet, schon die bloße Gefahr der Inanspruchnahme zu beseitigen. Allerdings muss der Sachverhalt, der Rechte Dritter entstehen ließ, bereits bei Gefahrübergang bestanden haben. § 442 BGB a. F. bestimmt, dass der Käufer das Vorliegen des Rechtsmangels zu beweisen hat.

Ein Rechtsmangel aufgrund eines Herausgabeanspruchs nach deutschem Recht besteht nicht. Ein Anspruch auf Herausgabe gemäß § 985 BGB scheidet aus, da die Klägerin - wie bereits ausgeführt - Eigentümerin geworden ist.

Es besteht auch kein Rechtsmangel aufgrund eines Rückerstattungsanspruchs nach einem Entschädigungsgesetz. Eine Einziehung nach öffentlich-rechtlichen Befugnissen kommt zwar grundsätzlich in Betracht, allerdings wurden die entsprechenden Ansprüche nicht rechtzeitig angemeldet.

Schließlich besteht auch kein Rechtsmangel aufgrund der vermeintlichen Beschlagnahme in den Vereinigten Staaten. Grundsätzlich können auch ausländische Rechte einen Rechtsmangel darstellen. Dies setzt jedoch voraus, dass für das geltend gemachte ausländische Recht eine Entsprechung in der deutschen Rechtsordnung besteht. Anderenfalls könnten gegen einen in Deutschland ansässigen Verkäufer Schadensersatzansprüche bestehen, deren Entstehung er nach deutschem Recht nicht vorhersehen konnte. Eine solche Erweiterung seiner 
Haftung wäre jedoch unbillig. Ein Käufer, der den Kaufgegenstand aus eigenen Stücken ins Ausland ausführt, ist diesbezüglich auch nicht schutzwürdig.

Vorliegend gibt es für die Beschlagnahme kein solches Äquivalent im deutschen Recht. Es erfolgte keine Beschlagnahme in einer dem deutschen Recht vergleichbaren Art und Weise aufgrund eines justizförmig gestalteten Verfahrens. Der Sicherstellung liegt eine "Stipulation", also eine Vereinbarung zugrunde, die nachträglich durch eine Erklärung des Justizministeriums bestätigt worden ist.

Soweit sich die Klägerin darauf beruft, dass das Bild der Beschlagnahme und Einziehung gemäß Title 19, United States Code, Section 1595 (a) (c) und Title 18, United States Code, Section 981 (a) (1) (C) als gestohlenes Eigentum, welches gegen Verstoß in die Vereinigten Staaten importiert wurde, unterliege, ist dieses Vorbringen unsubstantiiert. Die Klägerin hat ausschließlich die zugrunde liegende US-amerikanische Rechtsgrundlage bezeichnet und behauptet, dass ein Beschlagnahmeanspruch bestanden habe, den die zuständige Behörde jederzeit hätte durchsetzen können. Sie hat jedoch nicht dargelegt, ob für diesen angeblichen Beschlagnahmeanspruch eine Entsprechung im deutschen Recht besteht. Aus ihren Ausführungen geht nicht hervor, ob die US-amerikanische Rechtsgrundlage in einer dem deutschen Recht vergleichbaren Art und Weise eine Beschlagnahme regelt und welcher konkreten deutschen Vorschrift die Rechtsgrundlage entspreche. Diesbezüglich trifft sie jedoch gemäß § 442 BGB a. F. die Darlegungs- und Beweislast.

Die Klägerin hat auch keinen Anspruch auf Schadensersatz wegen einer vorvertraglichen Pflichtverletzung aus $\S \S 311$ Abs. 2, 241 Abs. 2, 280 Abs. 1 BGB. Es kann offen bleiben, ob ein solcher Anspruch zunächst entstanden ist, da dieser inzwischen in jedem Fall verjährt wäre. Gemäß § 214 Abs. 1 BGB ist der Schuldner nach Eintritt der Verjährung berechtigt, die Leistung zu verweigern.

Die Verjährung richtet sich nach den Vorschriften des BGB in der seit dem 1. Januar 2002 geltenden Fassung. Nach Art. $229 \S$ 6 Abs. 1 EGBGB finden auf Ansprüche, die am 1. Januar 2002 bereits entstanden, aber noch nicht verjährt waren, die neuen Verjährungsregeln Anwendung. War der Anspruch zwar noch nicht entstanden, beruht er aber auf einem „alten“ Schuldverhältnis, so gilt diese Regelung entsprechend (vgl. BGH, NJW 2006, 44). Nach Art. $229 \S 6$ Abs. 3 EGBGB gilt die neue Verjährungsfrist jedoch nur, wenn sie kürzer als die bis zum 1. Januar 2002 geltende ist. Dies ist hier der Fall. Die Verjährung würde nach altem Recht gemäß §§ 195, 198 BGB a. F. 30 Jahre ab Entstehung des Anspruchs betragen. Nach neuem Recht beträgt die regelmäßige Verjährungsfrist nur noch drei Jahre und die Höchstfrist nach $\S 199$ Abs. 3 Nr. 1 zehn Jahre.

Nach § 195 BGB, der die regelmäßige Verjährungsfrist regelt, ist noch keine Verjährung eingetreten. Für den Beginn der Verjährung gilt, unabhängig von § 229 § 6 Abs. 4 EGBGB ， 199 Abs.
1 BGB (BGH NJW 2007, 1584). Die Verjährung beginnt danach, wenn der Anspruch entstanden und der Gläubiger Kenntnis von den anspruchsbegründenden Umständen erlangt hat. Kenntnis hat die Klägerin nicht vor 2009 erlangt, sodass die Verjährungsfrist erst am 31. Dezember 2012 abgelaufen wäre.

Allerdings ist nach § 199 Abs. 3 Nr. 1 BGB Verjährung eingetreten. § 199 BGB regelt eine kenntnisunabhängige Höchstfrist der Verjährung. Danach verjähren Ansprüche unabhängig von der Kenntnis des Gläubigers innerhalb von zehn Jahren ab Entstehung des Anspruchs. Entstanden ist ein Anspruch, sobald er im Wege der Klage geltend gemacht werden kann. Ein Schadensersatzanspruch der Klägerin wäre bereits 2000 entstanden, als sie das Gemälde bei der Beklagten ersteigerte. Entgegen der Auffassung der Klägerin hat sich der Schaden nicht erst mit Übergabe an die amerikanischen Behörden und damit 2009 realisiert, sodass die Verjährungsfrist erst zu diesem Zeitpunkt beginnen würde. Vielmehr ist der Anspruch aus culpa in contrahendo bereits im Jahr 2000 entstanden, da ein etwaiger Beschlagnahmeanspruch und damit die Gefahr des Verlustes des Gemäldes bereits zu diesem Zeitpunkt bestand.

Wegen der Überleitungsvorschrift aus Art. $229 \S 6$ Abs. 4 EGBGB beginnt die Frist jedoch nicht bereits im Jahr 2000, sondern erst am 1. Januar 2002. Damit ist gemäß Art. $229 \S 6$ Abs. 4 EGBGB iVm § 199 Abs. 3 Nr. 1 BGB am 1. Januar 2012 Verjährung eingetreten. (Entscheidung von der Redaktion bearbeitet.) 